\title{
Sound of Ikebana: Creation of Media Art Based on Fluid Dynam- ics
}

\author{
Yunian Pang ${ }^{1}$, Hidekazu Tamai ${ }^{1}$, Naoko Tosa ${ }^{1}$, Ryohei Nakatsu ${ }^{2 *}$ \\ ${ }^{I}$ Graduate School of Advanced Integrated Studies in Human Survivability, Kyoto University, Kyoto 606-8306, \\ Japan \\ ${ }^{2}$ Design School, Kyoto University, Kyoto 606-8501, Japan
}

*Corresponding Author: Ryohei Nakatsu, Design School, Kyoto University, Kyoto 606-8501, Japan

\begin{abstract}
We have been working on the creation of media art, utilizing technologies. As fluids create beautiful forms under various conditions, we have been trying to utilize fluid dynamics as a basis for creating media art. However, most of the visualization results of the fluid dynamics show only stable fluid behaviors and lack of unstable or, in other words, unpredictable behaviors that would be significant in the creation of art. To create various unstable or unpredictable fluid behaviors, we have developed and introduced a new method called "Sound Vibration Form (SVF)" to control fluid behaviors and created amedia art called "Sound of Ikebana." Interestingly, people find and feel Japanese beauty in media art, although itis created based on a natural phenomenon. This paper proposes the basic concept of media art based on fluid dynamics, describes details of the SVF to create unpredictable fluid dynamics-based phenomena, and a new media art called "Sound of Ikebana" created utilizing SVF. Also, we will discuss the relationship between Japanese beauty and physical phenomena represented by fluid dynamics.
\end{abstract}

Keywords: Fluid dynamics, High-speed camera, Fluid art, Ikebana, Japanese beauty

\section{INTRODUCTION}

We have been creating media art during which new technologies play an important role. Recently, we've been curious about the usage of a high-speed camera, through which we've found hidden beauty in various natural/physical phenomena. Especially, we've been curious about fluid behaviors and have been trying to make media arts by capturing fluid behaviors employing a high-speed camera. Supported by this system, we've been trying to make new sorts of media art [1].

This area is named "fluid mechanics" or "fluid dynamics" and there has been a spread of research within this area [2][3]. As some fluid motions look beautiful, there's another research area called "visualization of fluid motion" [4]. However, most visualization results show only stable fluid behaviors and there are few unstable or, in other words, un-predictable behaviors. Such unstable or unpredictable behaviors are significant within the creation of art. Therefore, to understand various unstable or unpredictable fluid behaviors for artwork creation, it's important to introduce a new method of controlling fluid behaviors.

In this paper, we describe a way that has been developed and introduced by us to make new media art. Within the method, we used viscous fluids like paints with various colors, to which we applied vibration to supply upward motion and shot their "jumping-up" behaviors with a high-speed camera. it had been revealed that jumping-up paints create various forms that change during a very short time. However, control of the jumping-up behavior depends on many factors, like sound form, sound frequency, fluid amount, fluid viscosity, etc. We call such a group of parameters as Sound Vibration Form (SVF) and have administered systematic experiments to research the way to control the variables of SVF [5]. Utilizing the result, Naoko Tosa, one among the authors, shot various jumping-up paints by changing relevant parameters and carried out the editing of the obtained video, then a sort of media art called "Sound of Ikebana" was created [6].

She has exhibited her media arts including the Sound of Ikebana at various places throughout the world and has received comments on her media arts from many Western people including art curators, art critics, etc. Interestingly, they feel that there's Japanese beauty in these artworks. Why do they feel 
Japanese beauty within the visualization of natural/physical phenomena? For this, supported by our consideration, we've developed a hypothesis that one important factor of Japanese beauty comes from the extraction and expression of beauty hidden in natural/physical phenomena. Because the relationship between her media arts and Japanese beautyis primeforthe worthof such arts, we'll discuss the connection between natural/physical phenomena and Japanese beautywithin the last part ofthis paper.

This paper consists of the following subsequent sections. In Section 2, the essential concept of the visualization of fluid dynamics as a way to make artworks is going to be described. In Section 3 the research on variable control of SVF is going to bedescribed. In Section 4, a creation method of a media art supported by SVF is going to be described, and then the media art called "Sound of Ikebana" utilizing SVFare going to be described. In Section 5, a discussion on Japanese beauty is going to be administered and we will make a hypothesis that one important factor of Japanese beauty comes from the visualization of hidden beauty in nature. Finally, in Section 6, we'll conclude our discussion.

\section{FLUID DYNAMICS AND FLUID ART}

The study of the behaviors of fluid has been a long-time research topic in physics and this area is named "fluid dynamics" [2][3]. In physics, fluid dynamics may be a sub-discipline of hydraulics that deals with fluid flow. Fluid dynamics features a wide selection of applications such as calculating forces and moments on aircraft, predicting weather patterns, and so on. Determining the way to explicitly show the behavior of fluid is another research area called "visualization of scientific phenomena" [4]. Supported by this visualization process, it became possible for people to observe the particular process of fluid behavior and it's been recognized that various beautiful fluid motions are often created counting on various conditions. Figure 1 shows the results of the visualization of fluid behavior called "milk crown" [7]. As beauty is the fundamental element of art, utilizing fluid dynamics as a way to make artworks has been one of the key concepts of art creation. Various artworks utilize the concept of fluid dynamics. These approaches are often classified in two ways.



Fig1. Milk crown.

One approach is from a purely scientific side. Although various sorts of beautiful forms are often created supported by such approaches, created forms aren't considered pure art. The rationale for this is often that these phenomena or created forms are still based an excessive amount of physics and it's difficult to incorporate an "intention of artists" within the form creation process. There's a transparent distinction between physical phenomena and artworks and therefore the border is what proportion of the artists' intension to make artworks is involved within the created work. If there's no intention or the intention is just too weak, the created forms are considered as physical phenomena instead of artworks. In other words, forms created as physical phenomena are controlled by the laws of physics and there's little space for where something unexpected happens and this unexpectedness may be an essential part of artworks.

On the opposite hand, there's an approach that is from an art basis. During this case, how to use fluid is strongly controlled by artists and at the same time, unexpected phenomena or chance phenomena are utilized by the artists to incorporate something unexpected into their artworks. One representative of such art creation processes is "Action Painting" [8] led by Jackson Pollock [9]. Abstract Expressionism may be a sort of art creation during which, rather than drawing paintings employing a paintbrush, artists throw or draw paints on a canvas. Artists have intentions regarding what kinds of paint they use and where on the canvas they throw or draw paints. Therefore, additionally to the intentions of the artists, a sort of contingency caused by thrown or drawn paints influences the ultimate sort 
of the created artwork. Figure 2 shows one of the representative artworks of Pollock. Although he's now highly evaluated and appreciated within the modern history of art, it's difficult to seek out the natural beauty in his artworks, and, therefore, within the beginning, this confused many viewers.

Based on the issues included in these approaches, we expect that there should be a new and adequate art creation process somewhere in between these two approaches. We started from the previous approach but tried to incorporate more unexpectedness in created forms. We call artworks created based on our approach as "fluid art." In Section 3 and Section 4, a way of making fluid art and an example of created fluid art are going to be described.

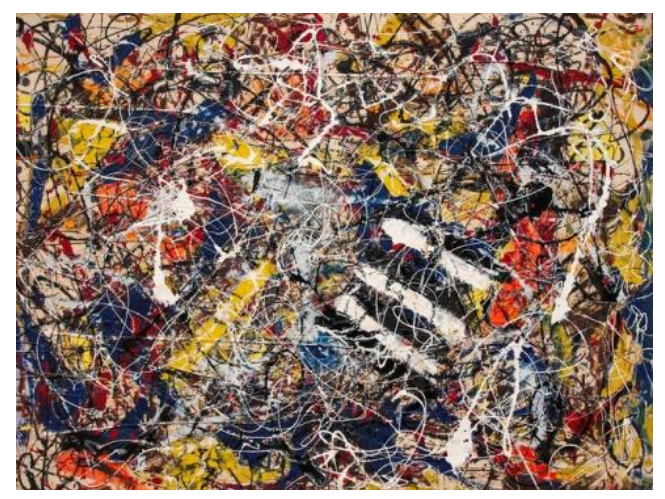

Fig2. One of Jackson Pollock's drawings. (in the public domain)

\section{VARiable Control of Sound Vibration Form (SVF) AS A Method of Creating Fluid ART}

As was indicated in the previous section, to create artworks based on fluid dynamics it is important to be able to control fluid behaviors to some extent and at the same time, there should be some space for unexpectedness to occur. For that purpose, we have developed a new art creation method called Sound Vibration Form (SVF), which generates various changing shapes of materials ejected up by sound vibration [5]. The vibration of the sound and generated material movements are so fast and we cannot see the phenomenon with our naked eyes. Therefore, we use a high-speed camera to record the phenomenon and replay it at an acceptable speed by human eyes. We used the rate of 2,000 frames per second and replayed it with 30 frames per second. This means we expanded real-time to 67 times ( 1 second expanded to 67 seconds). Then a beautiful phenomenon that is hidden in nature can appeal to our eyes directly.

To create the Sound Vibration Form, we upgrade the system studied by Chen et al. [1], which consists of the below parts.

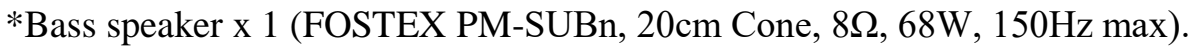

*Rubber sheet x 1 (250mmx250mmx0.5 mm).

*High-speed camera x 1 (NAC HX-3 4K 2000 frames per second).

*Computer x 2 (Each for speaker control and high-speed camera control).

*Illumination $300 \mathrm{~W}$ xenon light x 2 .

*Black background fabric x 1 .

*Materials for the experiment (viscosity controlled poster paint, jelly, foam, etc.)

The flowchart illustrated in Fig. 3 explains the creation process. First, we put a rubber sheet on the top of the bass speaker and stretch the rubber to make it have enough tension. Then we fix the rubber to make it stable. After this, we put various materials, whose quantity and viscosity are carefully controlled, on the rubber. A laptop computer is used to generate sound whose shape and frequency are controlled, and the generated sound source is fed to the speaker to play it. The vibration of the corn of the speaker then is delivered to the rubber andthe materials on it. The materials are forced to jump from the rubber rapidly. A high-speed camera is used to shoot the changing shape and another computer connected to the camera records this. Because the actual shapes of the materials are only around $5 \mathrm{~cm}-15 \mathrm{~cm}$ tall, we need to locate the camera close enough to the speaker to obtain better image quality. This can make the depth of the field shallow, and the motion of the materials can easily go out 
of range. To solve this problem, we adjust the aperture to the smallest size. Also,to realize a brightness for a better quality of shooting, we introduced two $300 \mathrm{~W}$ xenon lamps. This could maintain a wider depth of field. The top-down view of the system is illustrated in Fig. 4.



Fig3. The flowchart of Sound Vibration Form control.

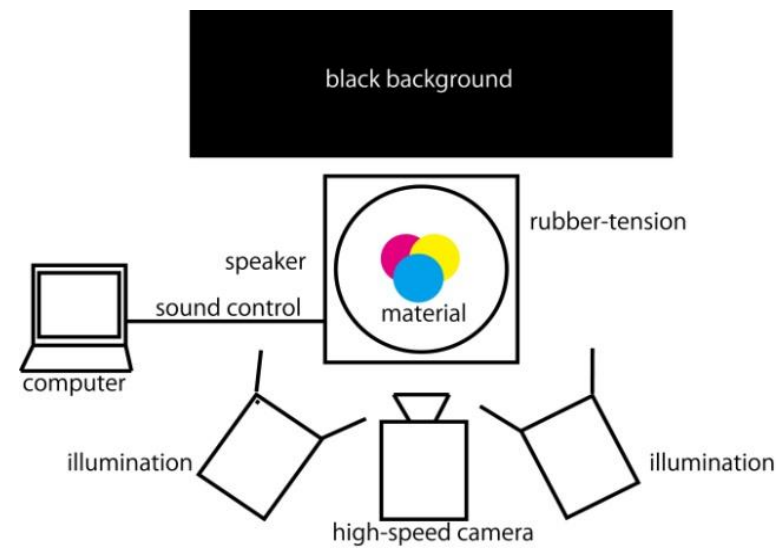

Fig4. Top-down view of the Sound Vibration Form system.

\subsection{Sound Control Program}

One of the key parameters is the sound wave frequency. For sound frequency control, we used the sound control software called Pure Data (PD) [10]. PD is an open-source visual programming language, which is concentrated on media programming, especially on music area or multimedia.
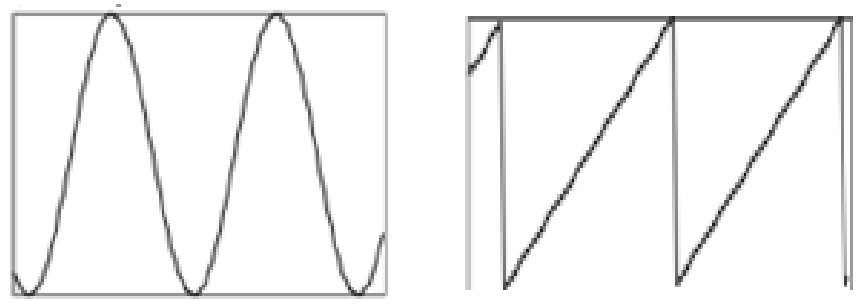

Fig5. The shape of sound waves generated by the program. (Left: Sine wave. Right: Zigzag wave.)

We created two types of waveforms using PD (Fig. 5). The left side of Fig. 5 is sine wave sound, and the right side is a zigzag wave.

\subsection{Experiments and Analysis}

We carried out various experiments systematically changing key parameters. Below is a brief explanation of the experiments.

\section{Viscosity}

Raw paint of white poster color was used here. We mixed the paint with water to control the viscosity. For each experiment, we used $20 \mathrm{~g}$ of paint and mixed it with water ranging from $0 \mathrm{~g}$ to $3.75 \mathrm{~g}$ with an increase of $0.25 \mathrm{~g}$ for each time. Figure 6 shows the result of the experiment. 


\begin{tabular}{|c|c|c|c|c|}
\hline $\begin{array}{l}\text { Observed phe- } \\
\text { nomenon }\end{array}$ & & & & \\
\hline $\begin{array}{l}\text { Weight of water } \\
\text { added for } 20 \mathrm{~g} \text { of } \\
\text { raw paint }\end{array}$ & $0 \mathrm{~g}$ & $0.25 \mathrm{~g}$ & $0.5 \mathrm{~g}$ & $0.75 \mathrm{~g}$ \\
\hline $\begin{array}{l}\text { Observed phe- } \\
\text { nomenon }\end{array}$ & & & & \\
\hline $\begin{array}{l}\text { Weight of water } \\
\text { added for } 20 \mathrm{~g} \text { of } \\
\text { raw paint }\end{array}$ & $1 \mathrm{~g}$ & $1.25 \mathrm{~g}$ & $1.5 \mathrm{~g}$ & $1.75 \mathrm{~g}$ \\
\hline $\begin{array}{l}\text { Observed phe- } \\
\text { nomenon }\end{array}$ & & & & \\
\hline $\begin{array}{l}\text { Weight of water } \\
\text { added for } 20 \mathrm{~g} \text { of } \\
\text { raw paint }\end{array}$ & $2 \mathrm{~g}$ & $2.25 \mathrm{~g}$ & $2.5 \mathrm{~g}$ & $2.75 \mathrm{~g}$ \\
\hline $\begin{array}{l}\text { Observed phe- } \\
\text { nomenon }\end{array}$ & & & & \\
\hline $\begin{array}{l}\text { Weight of water } \\
\text { added for } 20 \mathrm{~g} \text { of } \\
\text { raw paint }\end{array}$ & $3 \mathrm{~g}$ & $3.25 \mathrm{~g}$ & $3.5 \mathrm{~g}$ & $3.75 \mathrm{~g}$ \\
\hline
\end{tabular}

Fig6. Influence of viscosity (Sound frequency was 32Hz. Sound shape was sine. Quantity was set to 6g.)

According to the result of the experiments, we found that the paint is too sticky to jump up when water under $1 \mathrm{~g}$ was added. A beautiful paint shape could not be observed. For added water ranging from $0 \mathrm{~g}$ to $0.5 \mathrm{~g}$, the height of jumping paint is around $3 \mathrm{~cm}$. The shape of the paint had no division. For $0.5 \mathrm{~g}$ to $1 \mathrm{~g}$ added water, paint could jump up to $5 \mathrm{~cm}$. Several branches and layers of the paint form could be observed. For $1 \mathrm{~g}$ to $2 \mathrm{~g}$ added water, the characteristic Ikebana-like paint form could be observed clearly. In these cases, paints could jump up to $15 \mathrm{~cm}$, and had clearer branches. The mantle-like shape could be generated more frequently in this viscosity range. We consider that this viscosity range is best for artists to create artworks. For above $2 \mathrm{~g}$ added water, paints jumped higher, and paints were divided into a set of paint drops. When $2.5 \mathrm{~g}$ water was added, the paint could jump up to $25 \mathrm{~cm}$, with more paint drops generated. At this range, we consider that the viscosity was too low for art creation. The mantle-like shape could not be generated in this viscosity range. For $3 \mathrm{~g}$ to $3.75 \mathrm{~g}$ added water, paint could generate more branches and very easy to become droplets. Interesting thing is that the jumping height basically decreased, but occasionally the paint could jump up very high with over $30 \mathrm{~cm}$ height. 


\section{Quantity}

We carried out an experiment by changing the quantity of paint on the speaker from $2 \mathrm{~g}$ to $30 \mathrm{~g}$ with the step of $2 \mathrm{~g}$ keeping the same viscosity and observed the generated paint shape.Figure 7 shows the results.

\begin{tabular}{|l|l|l|l|l|}
\hline Paint quantity & $2 \mathrm{~g}$ & $4 \mathrm{~g}$ & $\mathrm{gg}$ & $\mathrm{g}$ \\
\hline $\begin{array}{l}\text { Observed phenome- } \\
\text { non }\end{array}$ & & & & \\
\hline
\end{tabular}

Fig7. Influence of quantity (Sound frequency was $32 \mathrm{~Hz}$. Sound shape was sine. Viscosity was set so that the ratio of $20 \mathrm{~g}$ raw paint mixed with $1.5 \mathrm{~g}$ water was kept.)

When only $2 \mathrm{~g}$ of paint was added, the jump of the paint could not be observed clearly. When $4 \mathrm{~g}$ paint was added, branches of paint could be observed, but not very high. The height was around $7 \mathrm{~cm}$ to $8 \mathrm{~cm}$. When $6 \mathrm{~g}$ paint was added, the paint height reached $20 \mathrm{~cm}$ and the characteristic paint form could be observed clearly. For $10 \mathrm{~g}$ to $14 \mathrm{~g}$ of added paint, we could observe more paint branches and the shapes were like a stream. For $16 \mathrm{~g}$ added paint, the characteristic mantle shape could be observed more easily. When the quantity reached $20 \mathrm{~g}$, mantle shape could be generated more often. For $22 \mathrm{~g}$ to $30 \mathrm{~g}$ of added paint, the results were almost similar to the result with $20 \mathrm{~g}$.

\section{Frequency of Sound Wave}

According to our preliminary experiments, we found that the paint on the FOSTEX PM-SUBn speaker started jumping up at $20 \mathrm{~Hz}$. So, the experiment started at $20 \mathrm{~Hz}$. We carried out experiments for each increase of $4 \mathrm{~Hz}$ starting from $20 \mathrm{~Hz}$ until $92 \mathrm{~Hz}$. The results are shown in Fig. 8. 


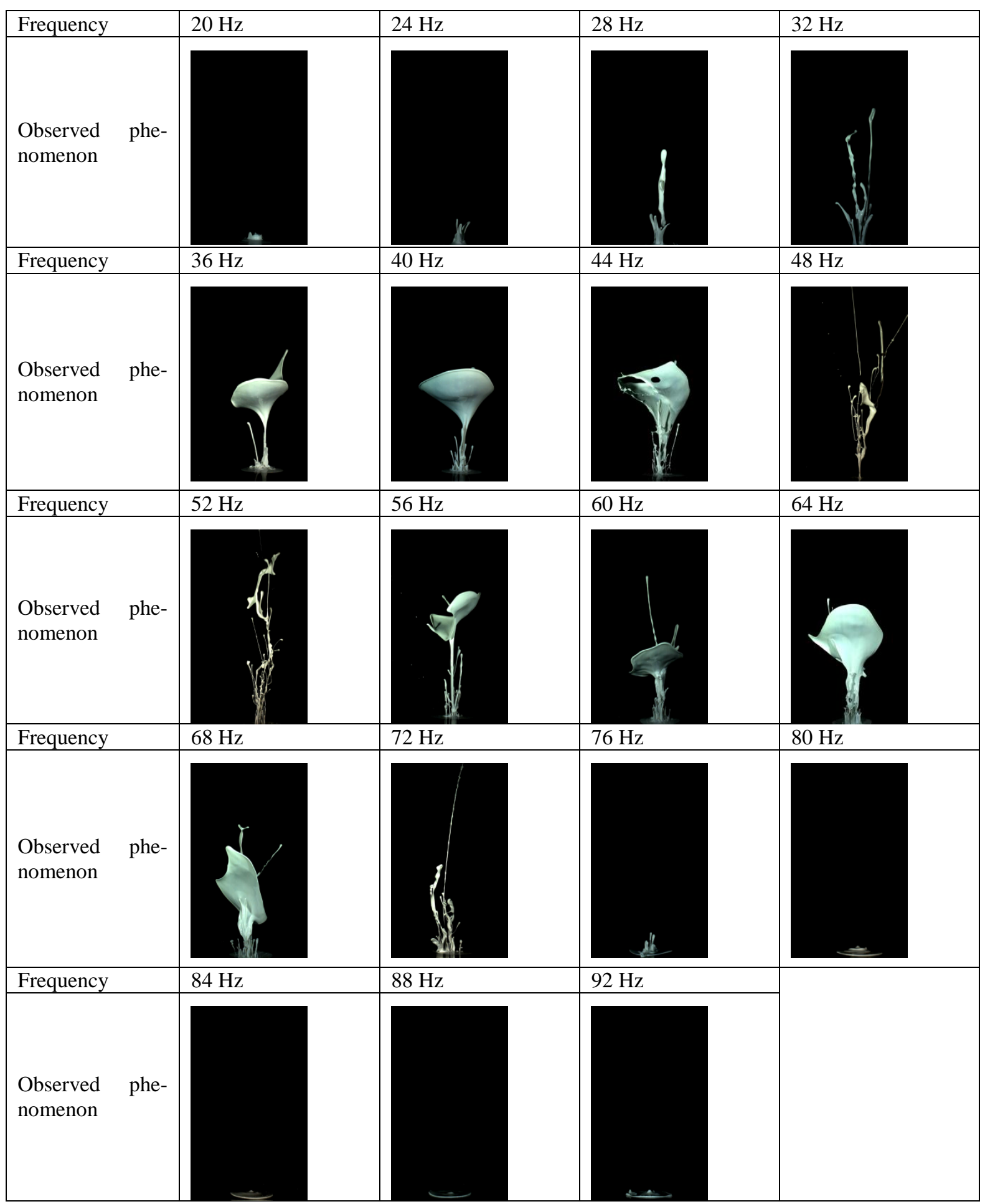

Fig8. Influence of sound frequency (Sound shape was sine. Viscosity was set so that the ratio of $20 \mathrm{~g}$ raw paint mixed with $1.5 \mathrm{~g}$ water was kept.)

The paint started to jump at 20Hz. First, the jump up height was low. But for a higher frequency, the jumping up height increased rapidly. When the frequency reached $24 \mathrm{~Hz}$, the paint could reach $5 \mathrm{~cm}$ height. And when it reached $28 \mathrm{~Hz}$, the paint reached $15 \mathrm{~cm}$ height. At the frequency of $32 \mathrm{~Hz}$, paint jumped higher with more branches. The height reached $20 \mathrm{~cm}$. For $36 \mathrm{~Hz}$ to $44 \mathrm{~Hz}$, we could observe that the mantle-like shapes were generated. For $48 \mathrm{~Hz}$ to $52 \mathrm{~Hz}$, the frequency became too high to create the mantle-like shape. Paint jumped higher than the case of $30 \mathrm{~cm}$. For $56 \mathrm{~Hz}$ to $68 \mathrm{~Hz}$, the mantle-like shape appeared again, but there are more branches near the foot of the paint. The height of jumped-up paint decreased to $20 \sim 25 \mathrm{~cm}$. At $72 \mathrm{~Hz}$, no mantle-like shape could be observed anymore. The shape of the paint was like a zigzag stream more and more. The height was lower than $15 \mathrm{~cm}$. For the higher frequency, jumped up paint dropped rapidly. For $76 \mathrm{~Hz}$ to $92 \mathrm{~Hz}$, paint could jump no more than $5 \mathrm{~cm}$. 


\section{Materials}

We carried out several experiments changing the materials to be jumped up. Figure 9 shows the results.

\begin{tabular}{|l|l|}
\hline Material & Observed phenomena \\
\hline Water & $\begin{array}{l}\text { Water jumped up from the center of the tensioned } \\
\text { rubber and then rapidly change to small sphere } \\
\text { shaped drops. And it jumped very high. The highest } \\
\text { drop reached over 50cm. The average was 40cm. }\end{array}$ \\
\hline Paints & $\begin{array}{l}\text { The height that jumped up paints reached is only half } \\
\text { of water's case. And it didn't separate to small drops } \\
\text { and maintained an unbroken shape. Finally, it } \\
\text { changed to stream shape. The height of the paint was } \\
\text { 25cm. }\end{array}$ \\
\hline Foam & $\begin{array}{l}\text { Shough the shape of foam changed a lot, it didn't } \\
\text { separate. The foam only reached the height of 10cm. } \\
\text { Jubber, but didn't jump at all. }\end{array}$ \\
\hline
\end{tabular}

Figure9. Influence of viscosity for different materials (Sound frequency was $32 \mathrm{~Hz}$. Sound shape was sine.)

\section{The shape of the sound wave}

Figure 10 shows the results of the change of the sound wave shape.

\begin{tabular}{|l|l|l|}
\hline Type of wave & Observed phenomena \\
\hline Zine wave & $\begin{array}{l}\text { The vibration provided by } \\
\text { sine wave could create sig- } \\
\text { nificant form. The height of } \\
\text { the paint reached at most } 30 \\
\text { cm. }\end{array}$ \\
\hline $\begin{array}{l}\text { The vibration provided by } \\
\text { zigzag wave could not even } \\
\text { make paint jump up. This } \\
\text { phenomenon happened no } \\
\text { matter which sound fre- } \\
\text { quency we chose. }\end{array}$ \\
\hline
\end{tabular}

Fig10. Influence of the shape of sound wave (Paint was set to medium viscosity. Quantity was set to 10g. Sound frequency was set to $32 \mathrm{~Hz}$.)

\section{AN EXAMPLE OF FLUID ART: SOUND OF IKEBANA}

The systematic experiments of Sound Vibration Form(SVF) described in the previous section revealed the relevant range for each parameter.Utilizing these results one of the authors, Naoko Tosa, carried out various experiments by changing the type of sound, sound frequency, liquid type, liquid viscosity, etc. within the relevant range, and based on this, she created an artwork called "Sound of Ikebana." In this artwork, the sound was used as an energy source that can eject color paint up above the speaker. Then a high-speed camera was used to capture the motion of the paints. By expanding the time of the phenomena, people can see the beautiful shape of the paint, which looks like "Ikebana," the Japanese flower arrangement.

On the basis of this artwork, there is a traditional Japanese flower arrangement culture which will be discussed in the next section. At the same time, the latest technology is utilized. The Sound of Ikebana consists of four short videos, each of which represents one of the four seasons in Japan. It uses specific colors to represent flowers in each season (Fig.11). By utilizing various types of color paints and 
liquids, she tried to express Japanese flowers in each season.Spring is featuredby plum and cherry, summer by cool water and morning glory, autumn by red leaves, and winter by snow and camellia. Additionally, she tried to express various color variations such as prayerful colors of Buddhism, Japanese "Wabi, and Sabi" (austere beauty and elegant simplicity) colors, colors of delicious food, gorgeous colors featuring the New Year season, etc.

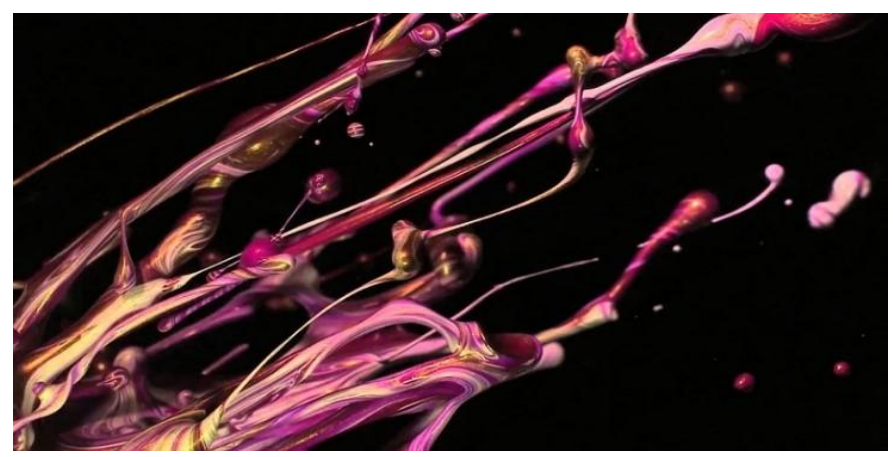

Fig11. A scene from "Sound of Ikebana".

By watching these series of video artworks, the audience would understand different beauty depending on each season in Japan and also transition from one season generated by the organic and mysterious figures of and also the unforeseeable movements of the fluids. At the same time, the audience would feel the connection between the long history and traditional cultures in Asia.

To display artworks to many audiences in an effective way, projection mapping has been frequently used. We carried out the projection mapping of the Sound of Ikebana at the Singapore ArtScience Museum in 2013. The moving images of the Sound of Ikebana were projected on the wall of the lotuslike ArtScience Museum. The artwork became a part of the city night view, and the whole city was able to appreciate it (Fig. 12). Also, the artwork was exhibited in Times Square in New York for one month in April 2017, using more than 60 digital billboards there (Fig. 13).

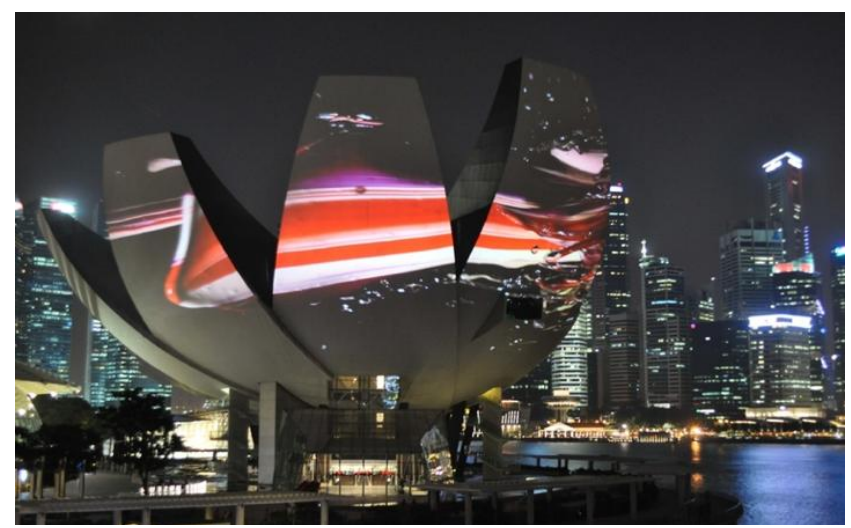

Fig12. Projection mapping of Sound of Ikebana at ArtScience Museum in Singapore.

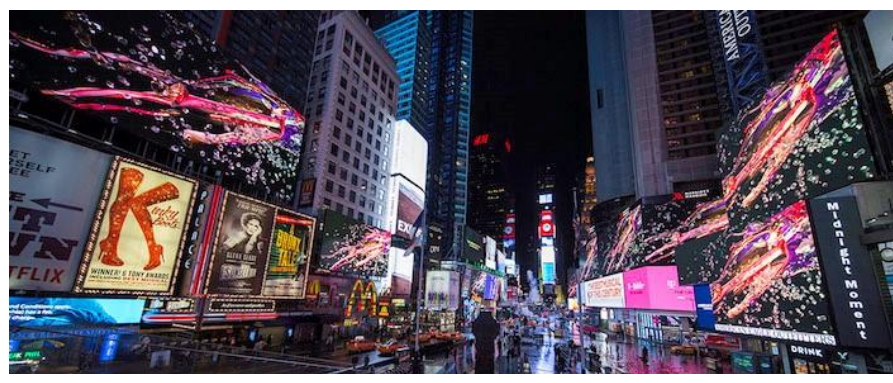

Fig13. Sound of Ikebana exhibited in Times Square, New York.

\section{FLUID ART AND JAPANESE BEAUTY}

As described within the previous section, the media art Sound of Ikebana was created utilizing fluid dynamics. Therefore, the idea of the art creation process is based on the physical/natural phenomenon. However, during the method of exhibiting the media art, we've experienced a stimulating reaction of individuals. In 2016 the Agency of Cultural Affairs, the Japanese Government named Naoko Tosa as 
Japan's Cultural Envoy and she exhibited her artworks including the Sound of Ikebana in more than ten cities over the world. During such exhibitions, she received many responses from many people including art critics, art curators, and general public. They said that "By showing beauty in hidden nature, Naoko Tosa's artworks express what we have not noticed. The essence of Japanese sensitivity is included in her artworks." It sounds strange that Western people feel that there's Japanese beauty in artworks created utilizing natural/physical phenomena. In this section, we'll discuss this issue comparing Western and Eastern sensitivities toward nature.

The creation of artworks expressing beauty in nature isn't a thought specific to Japan. This concept has been shared in many countries and cultures. Within the West, since the Greek era, the thought that art is "imitation of nature" has long been accepted [11] and this concept became the basis of the inventions of art techniques like perspective. However, by the invention of the camera, this concept was gradually replaced by another concept that art is the "expression of humans" inner life" and this trend continues through art movements like Impressionism, Cubism, Abstract Expressionism [12].

On the opposite hand, within the East, these theories haven't been the mainstream within the art world, and therefore the basic concept of Eastern Monism that stresses the unification of humans and nature has been dominant [13]. Although the concept of shadows and perspectives have played important roles in Western art, Eastern artists have neglected them. Having the thought of the unification of humans and nature deep in their minds and using their sensitivities, Eastern artists have created their artworks and also their art world. In China, for instance, monochrome ink paintings of landscapes have been popular. In such landscape paintings, which are supported by the old Chinese philosophy of Taoism [14], Chinese artists tried to draw ideal landscapes, in other words Arcadia.

As Japan continuously imported Chinese cultures, Japanese art was deeply influenced by Chinese art. Then gradually merging this with the feeling of Japanese people, Japanese artists began to make their artworks without shadows and being planar, exaggerated, etc. Especially the isolation policy within the Edo era strengthened this trend. As the Japanese artworks within the modern art era look very fresh to the Western people, who has denied the thought of "imitation of nature," in the modern era, the movement called Japonism occurred [15].

Consequently, we interpret the impressions of Western people toward Naoko Tosa's artworks, when they say that her artworks express Japanese beauty, within the following way. The concept of art within the West has changed from its original idea of "imitation of nature" to the modern and present one of "expression of human's inner thought or concept." Contrast to Western art, Naoko Tosa's artworks are created based on capturing and extracting beauty in nature. Probably this is why her artworks appeal to their sensitivity and made them feel Japanese beauty in her artworks. Supported by this consideration we make a hypothesis that "One of the important factors comprising Japanese beauty is the extraction and expression of beauty in nature." Several examples are going to be shown as follows.

In natural phenomena, like water flow or waveforms, Japanese artists found beauty and by expressing such beauty, they created their artworks. One such kind is the well-known artworks by Katsushika Hokusai [16]. Also, the precise expression of water flow, called "Korin wave," designed by Ogata Korin is extremely documented [17]. Such artworks are typical expressions of Japanese beauty and are welcomed by Western artists, giving them strong impressions. Figure 14 shows "The great wave off Kanagawa, from 36 Views of Mountain Fuji," a print by Hokusai [18]. Interestingly, the dynamic waveform expressed well resembles the waveform shot by a high-speed camera. Figure 15 illustrates the fluid form created by injecting air-gun bullets into fluid with color paints. It's interesting to understand the resemblance between these two.

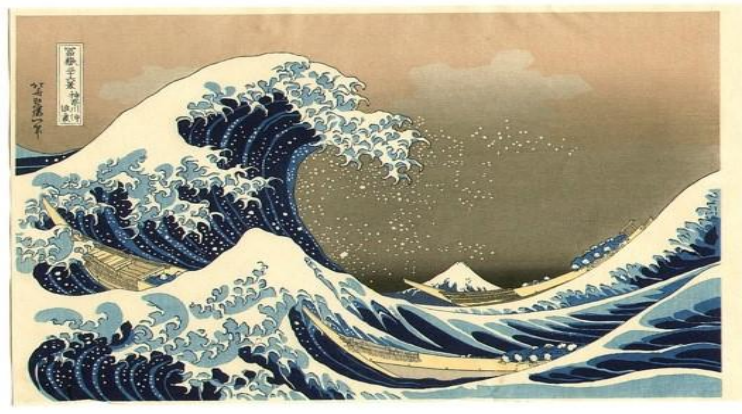

Fig14. "The Great Wave off Kanagawa, from 36 Views of Mountain. Fuji" by Hokusai. (in the public domain) 




Fig15. Fluid form captured by a high-speed camera.

Another example may be a basic sort of Japanese "Ikebana" (flower arrangement). The essential sort of Ikebana has been considered an "asymmetric triangle" (Fig. 16). Interestingly, many scenes within the Sound of Ikebana show good resemblance with this basic sort of Ikebana as is shown in Fig. 17.

What produces this resemblance between the artworks expressing the sort ofJapanese beauty and natural/physical phenomena? Probably great Japanese artists represented by Hokusai could find the beauty hidden in natural/physical phenomena using their mind's eye and could create artworks expressing the beauty they found. For now, this remains a hypothesis, but we would like to reveal this by continuing the creation of artworks expressing beauty hidden in nature.

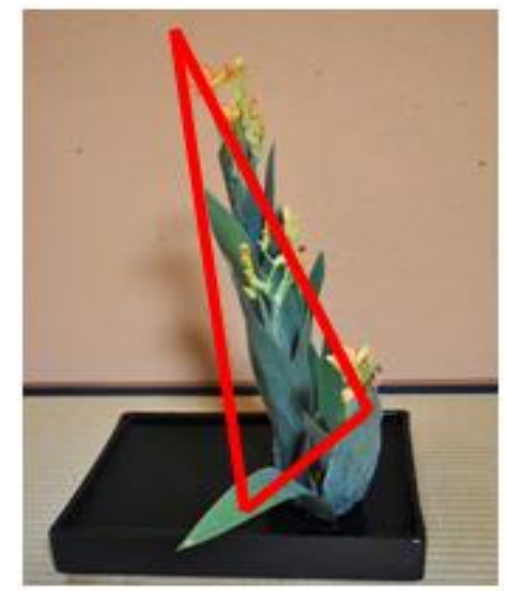

Fig16. "Basic Sort" of Ikebana. (in the public domain)

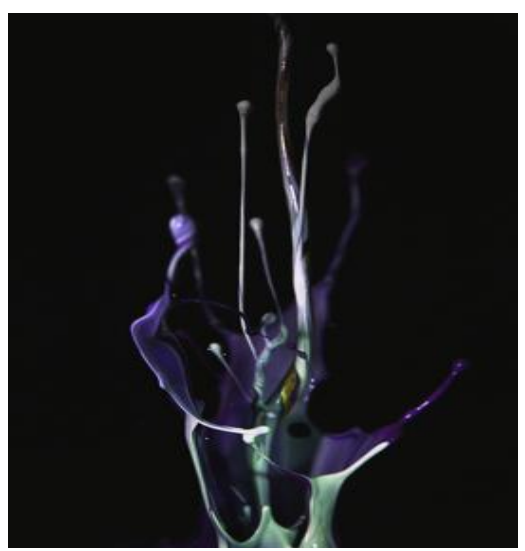

Fig17. An example of fluid form of Sound of Ikebana.

\section{CONCLuSion}

In this paper, we proposed a new type of media art creation method and described their details. The basis of the method is fluid dynamics, which is a research area to study behaviors of fluid. As we know that fluids can create various beautiful forms depending on conditions, it is natural to try to utilize fluid dynamics as a methodology of creating artworks. 
In Section 2, we described briefly what fluid dynamics is and then described the relationship between fluid dynamics and art creation. There are two approaches of utilizing fluid dynamics; one is to use physical phenomena of fluid as purely as possible and the other is to use fluid only as a material for art creation. It is important to utilize the mechanism of fluid dynamics to create beautiful forms and therefore we adopted the former method. However, if we try to utilize pure physical phenomena, it is difficult to include in the created artwork intention of artists. At the same time, it is important to include unexpectedness or unpredictability in the art creation process. Based on this we have developed a new method to control behaviors of fluid called Sound Vibration Form (SVF). SVF is a method to create a various fluid form by giving viscous fluid sound vibration. As there are various parameters to control the fluid behavior such as sound frequency, fluid viscosity, etc. we carried out a systematic experiment to know the effect and relevant range of each parameter, which was described in Section 3.

Then in Section 4, we described details of media art called "Sound of Ikebana," which was created by one of the authors, Naoko Tosa, utilizing the SVF. Based on the systematic research of SVF, an adequate range of each parameter became clear. At the same time, there is large freedom for the artist to control selection of the combination of the parameters and after many trials, she succeeded in the creation of beautiful fluid forms and created a media art called "Sound of Ikebana." The details of its creation process and how it has been exhibited in many places were described.

In Section 5 the relationship between the Sound of Ikebana and Japanese beauty was described. We have noticed and believe that at the basis of Japanese beauty there is the concept of the extraction of hidden beauty from nature. This may be the reason why one of the authors, Naoko Tosa, received many comments/opinions from people all over the worldsaying that they feel there is Japanese beauty in her artworks. We discussed this issue by showing several representative Japanese artworks and concluded that, in Japanese art history, the extraction of hidden beauty in nature and the expression of it as artworks has been the mainstream.

Of course, it is not relevant to try to connect fluid dynamics directly to artworks including Japanese beauty [19]. It is not our intentions to claim that fluid dynamics-based artworks are the only ones expressing Japanese beauty. At this stage, what we want to claim is the following. We have developed a method to create beautiful forms based on fluid dynamics. The creation process is closely connected to natural/physical phenomenon. As Japanese have had sensitivity that is closely related to beauty included in natural phenomenon, it was easy for one of the authors, a Japanese artist, to include her sensitivity and aesthetics into various art creation processes such as color selection, parameter selection for the SVF, editing of obtained video and so on. We will further study what Japanese beauty is and what the essential art creation process is to include Japanese beauty.

\section{REFERENCES}

[1] Feng Chen, Tomoji Sawada, Naoko Tosa: Sound Based Scenery Painting. 2013 International Conference on Culture and Computing, IEEE Press (2013).

[2] Bruce R. Munson, Alric P. Rothmayer, Theodore H. Okiishi, and Wade W. Huebsch: Fundamentals of Fluid Mechanics. Wiley (2012).

[3] Peter S. Bernard:Fluid Dynamics. Cambridge University Press (2015).

[4] Tee Tai Lim, Alexander J. Smits, eds.:Flow Visualization: Techniques and Examples. Imperial College Press (2012).

[5] Yunian Pang, Lian Zhao, Ryohei Nakatsu, Naoko Tosa: A Study on Variable Control of Sound Vibration Form (SVF) for Media Art Creation. 2017 Conference on Culture and Computing, IEEE Press (2017).

[6] Yunian Pang, Naoko Tosa: New Approach of Cultural Aesthetic Using Sound and Image. 2015 International Conference on Culture and Computing, IEEE Press $\{2015\}$.

[7] Rouslan Krechetnikov, George M. Homsy: Crown-forming Instability Phenomena in the Drop Splash Problem. Journal of Colloid and Interface Science, Vol.331, No.2, pp.555-559 (2009).

[8] Robert Fleck, Jason Kaufman, Gottfield Boehm: Action Painting. Hatje Cantz (2008).

[9] Ellen G. Landau: Jackson Pollock. Harry N. Abrams (2010).

[10] Home page of Pure Data: https://puredata.info/

[11] Aristotle, "The Art of Rhetoric," Penguin Classics (1992).

[12] Marilyn Stokstad, Michael W. Cothren, “Art History,” Pearson (2017).

[13] John Veitch, "Dualism and Monism, and Other Essays," Wentworth press (2019).

[14] Eva Wong, "Taoism: An Essential Guide," Shambhara (2011).

[15] Siegfried Wichmann, "Japonisme: The Japanese Influence on Western Art Since 1858," Thames \& Hudson (1999). 
[16] Sarah Thompson, Joan Wright:Hokusai. MFA Publications (2015).

[17] Masayuki Fujiura:KORIN: Japanese Aesthetics and Design. Pilkington Foundation Publications (2018).

[18] Timothy Clark: Hokusai: Beyond the Great Wave. London: Thames and Hudson (2017).

[19] Naoko Tosa, Yunian Pang, Qin Yang, RyoheiNakatsu, "Pursuit and Expression of Japanese Beauty Using Technology," Special Issue "The Machine as Artist (for the 21st Century)," Arts journal, MDPI, Vol.8, No.1, 38, DOI 10.3390/arts8010038 (2019.3).

\section{AUTHORS' BIOGRAPHY}

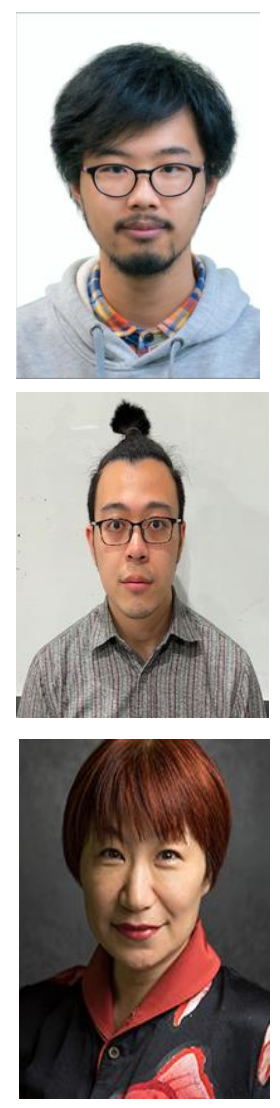

Yunian Pang, received B.S. degree from Southwest University of Political Science \& Law in China in 2014. Then he obtained M.S. degree from Graduate School of Advanced Integrated Studies in Human Survivability (GSAIS), Kyoto University in 2019. Now he is Assistant Professor at GSAIS, Kyoto University.

Hidekazu Tamai, received B.S. degree from Faculty of Law, Kyoto University in 2020. Now he is a Ph.D. student at Graduate School of Advanced Integrated Studies in Human Survivability, Kyoto University. ty by integrating art and technology. Ph.D. (Engineering)

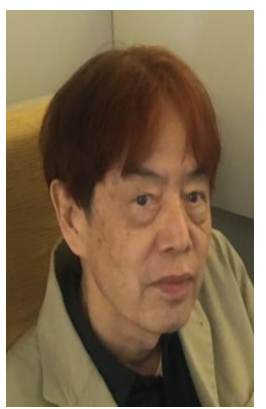

RyoheiNakatsu, received the B.S., M.S., and Ph.D. degrees in electronic engineering from Kyoto University in 1969, 1971, and 1982 respectively. After joining NTT in 1971, he mainly worked on speech recognition technology. In 1994, he became Director of ATR Media Integration \& Communications Research Laboratories. In 2002 he became Professor at the School of Science and Technology, KwanseiGakuin University. From March of 2008 until December 2014, he was Professor at the National University of Singapore (NUS) and was Director of Interactive \& Digital Media Institute (IDMI) at NUS. Now he is serving as Adjunct Professor of Design School at Kyoto University.

Citation: Ryohei Nakatsu, et.al. " Sound of Ikebana: Creation of Media Art Based on Fluid Dynamics" International Journal of Humanities Social Sciences and Education (IJHSSE), vol 8, no. 3, 2021, pp. 90-102. doi. https://doi.org/10.20431/2349-0381.0803009.

Copyright: (c) 2021 Authors. This is an open-access article distributed under the terms of the Creative Commons Attribution License, which permits unrestricted use, distribution, and reproduction in any medium, provided the original author and source are credited. 